\title{
AS IMAGINAÇÕES DA CIDADE: PRÁTICAS CULTURAIS JUVENIS E PRODUÇÃO IMAGÉTICA
}

\author{
Alexandre Barbosa Pereira ${ }^{1}$
}

\section{Juventudes, diferenças e imagens no espaço urbano}

"Quando ele colocou o microfone, que ele abriu a mala, eu: Me libera nega, deixa eu te amar. Aí tomou a cidade toda, mas saiu do fundo de uma viatura, de um camburão". Esse é o modo como Ítalo, um jovem negro, cujo nome artístico é MC Beijinho, resumiu a sua primeira aparição pública como cantor, em entrevista dada à TV Folha ${ }^{2}$. Em 18 de novembro de 2016, preso após roubar telefones celulares em praia da cidade de Salvador, Bahia, Ítalo, de 19 anos, já na viatura a caminho da delegacia, canta a música que compôs: Me libera nega. Um dos policiais resolve, então, chamar um telejornal policial local para registrar o fato. Pronto, criada a oportunidade para a construção da imagem sob medida para Ítalo. O repórter se aproxima e, ao abrir a viatura para a notícia policial, em vez de um bandido perigoso, quem sai é MC Beijinho, algemado com as mãos para trás, cantando. $\mathrm{O}$ delegado do caso, segundo a matéria da Folha de S. Paulo, chega a cogitar se Ítalo teria planejado a ação para justamente aparecer na televisão. De todo modo, estava feita a fama do rapaz. $\mathrm{O}$ vídeo foi rapidamente difundido pelas redes sociais, tornando-se matéria nos principais jornais e telejornais da Bahia e do Brasil. Artistas já consagrados como Caetano Veloso passaram a cantar a música, Me Libera Nega, em seus shows. MC Beijinho grava um videoclipe da música e se torna uma das atrações de um trio elétrico no famoso carnaval de Salvador.

Esse evento envolvendo MC Beijinho sumariza uma série de aspectos que pretendo aqui abordar, para discutir as disputas em torno da imagem dos jovens pobres no Brasil. O primeiro e mais fundamental aspecto refere-se a como muitos jovens, mesmo nas condições mais adversas, inventam contra-dispositivos para manipular as estruturas que os oprimem, reinventando muitas vezes imagens que os estigmatizam. MC Beijinho, após ser preso

\footnotetext{
${ }^{1}$ Universidade Federal de São Paulo, Brasil.

${ }^{2}<$ http://www1.folha.uol.com.br/ilustrada/2017/01/1853701-mc-beijinho-saiu-da-delegacia-para-o-topo-dasparadas-com-me-libera-nega.shtml>. De 29/01/2017.
} 
roubando telefones celulares na praia, começa a cantar sem parar uma música que compôs $\mathrm{e}$, na entrevista que concede sobre o caso, afirma ter comemorado quando os policiais disseram, ainda na viatura, que chamariam a reportagem televisiva para registrar o fato. Assim, uma das principais responsáveis por construir imagens estigmatizadas sobre os jovens pobres e negros no Brasil, tem seu objetivo subvertido pela genialidade tática de MC Beijinho. Ao sair cantando a música Me Libera Nega, ela deixa de ser simplesmente o vilão, que os telejornais policiais costumam construir, para se tornar também o personagem cômico a atrair a atenção para si e para sua música, pedindo, inclusive, ao repórter policial uma oportunidade para divulgar seu trabalho. Assim, MC Beijinho recusa, ao mesmo tempo, o papel de vítima e de vilão, para mostrar-se como artista.

Há mais de 15 anos sigo acompanhando em São Paulo uma série de práticas culturais juvenis, que, em alguma medida, dialoga com várias questões suscitadas por esse evento que levou MC Beijinho à fama, como a pixação, o funk ostentação e os rolezinhos. Em todas essas práticas há um processo múltiplo e diversificado de produção de imagens e imaginários. Por um lado, há as imagens que os próprios adeptos e/ou protagonistas dessas práticas produzem sobre si, baseados nas imagens que recebem das muitas mídias, principalmente a televisão, a internet e as redes sociais. Por outro lado, há as múltiplas imagens que essas mesmas mídias produzem sobre esses jovens. Trata-se, assim, de um processo de muitas vias em que os atores sociais considerados jovens produzem imagens inspirados pelas imagens que recebem todos os dias e, posteriormente, têm sua imagem reproduzida, muitas vezes de forma estereotipada e estigmatizante, pelas mesmas mídias em que se inspiram. Essas práticas culturais juvenis são apresentadas muitas vezes na chave do exótico, do espetacular e, até mesmo, da delinquência.

Desse modo, tomando o funk como ponto de partida, o que se pretende é analisar diferentes práticas culturais juvenis que são protagonizadas fundamentalmente por jovens das camadas populares que vivem em bairros periféricos, a partir de suas especificidades e complexidades. Para realizar esse exercício, tomo como referência três experiências de pesquisa sobre grupos, práticas e espaços marcadamente juvenis na cidade de São Paulo, abordados durante minha trajetória acadêmica: a "pixação", as sociabilidades juvenis em

\footnotetext{
${ }^{3}$ A palavra "pixação" será escrita aqui conforme a norma estabelecida por seus autores, com X. Para mais, ver Pereira (2005).
} 
escolas de ensino médio e o próprio funk associado aos eventos que ele suscitou e ainda suscita, como as festas na rua os rolezinhos nos shopping centers. Por práticas culturais juvenis compreendo as atividades protagonizadas por sujeitos considerados jovens ou que carregam fortemente uma marca simbólica daquilo que as sociedades industrializadas e urbanas definem como juvenil. Essas práticas culturais seriam realizadas fundamentalmente no momento do denominado tempo livre ou de lazer. Desse modo, tento abordar determinadas atividades sociais e culturais que têm certa referência juvenil, mas que não necessariamente se restringem a uma faixa etária e mesmo podem ser praticadas por não jovens.

Em discussão sobre as abordagens antropológicas e sociológicas da noção de juventude, Mary Bucholtz (2002) afirma que é preciso pensá-la como categoria cultural, o que implica atentar para como ela é produzida por determinadas relações sociais, mas também para como agencia relações. Segundo a autora, é preciso mudar o foco da definição dominante de juventude que a delimita no âmbito dos ritos de passagem, compreendendo-a sobretudo na chave da noção de adolescência; ou seja, principalmente, como transição psicobiológica para a vida adulta. Trata-se, portanto, conforme enfatizam Dayrell, Moreira e Stengel (2011) de compreender os jovens como sujeitos em construção, mas não apenas como um "vir-a-ser" adulto, pois sua atuação se dá de modo bastante intenso no presente. Assim, abordar os fenômenos que são considerados juvenis ou protagonizados por sujeitos considerados jovens como práticas culturais juvenis implica assumir que a noção de juventude é inventada e reinventada constantemente pela atuação dos mais diferentes agentes, sejam eles classificados como jovens ou não.

Autores como Mario Margulis e Marcelo Urresti (1996), por exemplo, também enfatizam $^{4}$ a necessidade de se pensar a juventude como uma categoria que produz sentidos e transforma relações. Pode-se afirmar que a noção ocidental contemporânea de juventude tem como os principais fatores que explicam sua configuração, a expansão do processo de escolarização, a urbanização e o surgimento de uma indústria cultural com uma proposta voltada justamente para o segmento considerado jovem. Contudo, tais autores retomam também a reflexão da psicologia estadunidense, que afirma justamente a juventude como

\footnotetext{
${ }^{4}$ Avançando a discussão de Bourdieu (1983) de que a juventude seria apenas uma palavra e, portanto, uma categoria relacional que só faria sentido na contraposição entre mais jovens e mais velhos, pois se é sempre jovem e/ou velho em relação a alguém.
} 
um período de crise por conta da necessidade de adaptação à vida adulta - mais uma vez, a ideia de transição, mal resolvida ou conflituosa nesse caso, para explicá-la - e que, por isso, seria preciso conceder aos mais jovens uma moratória. Ou seja, um período de preparo para a vida adulta que fosse desobrigado das responsabilidades que esta costuma acarretar.

Margulis e Urresti (1996), entretanto, afirmam que essa moratória não se distribui de modo igual para todas as camadas da população. Assim, enquanto aos jovens mais abastados há maior possibilidade, tempo e recursos financeiros para desfrutar dessa moratória juvenil, livre de obrigações, podendo apenas estudar e consumir os itens e signos juvenis, os jovens pobres teriam muito mais dificuldade de vivenciá-la, pois lhes faltariam tempo e recursos para tanto. Muitos têm de começar a trabalhar cedo para ajudar a família ou não têm condições de comprar os produtos que são identificados como típicos da juventude (hoje em dia, roupas de grife, telefones celulares, tablets etc.; em outros tempos, havia os discos das bandas preferidas, por exemplo). Quando se trata de meninas pobres, a questão de gênero pode ampliar ainda mais a desigualdade de acesso a essa moratória juvenil, pois é imposto a muitas delas desde muito cedo ajudar no trabalho doméstico e no cuidado de irmãos mais novos e, caso ocorra uma gravidez precoce, as obrigações consideradas típicas da vida adulta chegam com ainda mais força e precocidade. Os autores afirmam também que, ao mesmo tempo, todos os jovens, independentemente de suas condições sociais, compartilhariam de modo semelhante o que chamam de uma moratória vital ou energética, caracterizada por uma maior disposição física e uma sensação de que a morte estaria distante, o que permitiria um maior gasto da energia vital excedente. Dessa maneira, se todos podem ser jovens, no sentido biológico e/ou cronológico do termo, nem todos podem vivenciar a juventude, tal qual o ideal que é comumente propagado.

A noção de juventude mostra-se, portanto, como um artefato híbrido que remeteria a fatores biológicos, cronológicos, geracionais, culturais e econômicos. Assim, é possível haver jovens que desfrutam plenamente de sua moratória social e por isso vivenciam plenamente o signo de ser jovem na sociedade contemporânea, da mesma forma como há aqueles que não têm condições de usufruir desse período mais livre de responsabilidades ou o viveriam de modo inconstante e fragmentário, não experienciando, portanto, uma condição juvenil mais plena. Por isso, conforme Margulis e Urresti (1996), é possível falar de jovens juvenis, jovens não juvenis e não jovens juvenis. Ou seja, jovens que desfrutam 
plenamente de sua condição juvenil, jovens que não o conseguem e, o que tem se tornado cada vez mais comum nos últimos tempos, pessoas que seriam classificadas como fora do que seria convencionado como os limites da categoria etária jovem, mas que, por terem condições sociais e recursos financeiros, querem continuar desfrutando de determinados símbolos considerados como representativos da juventude na atualidade.

No Brasil, Juarez Dayrell (2007) argumenta que o trabalho para os jovens mais pobres é também uma forma de obter recursos financeiros para vivenciar essa moratória, que lhes permite, assim, participar de atividades de lazer e consumo consideradas tipicamente juvenis. Dessa maneira, ao evocar a noção de prática cultural juvenil, discuto-a a partir do modo como se configuram essas representações simbólicas do que seria ser jovem no mundo contemporâneo, sem a associar rigidamente a uma categoria etária. Assim, por práticas culturais juvenis posso tratar da atuação de jovens ou de não jovens. Quando pensadas de forma mais independente da dimensão etária, elas podem também constituir, em muitos casos, formas de prolongar o período de uma certa concepção de juventude, caracterizada como um momento da vida mais livre de obrigações do mundo do trabalho e da vida adulta.

Podemos dizer que, através do rap ou do funk, os jovens vivenciam a tentativa de alongar o período da juventude o máximo que podem, experienciando assim uma moratória. O sentido dessa tentativa não é tanto o de uma suspensão da vida social ou de irresponsabilidade, como geralmente é vista, mas de garantir espaços de fruição da vida, de não serem tão exigidos, de se permitirem uma relação mais frouxa com o trabalho, de investirem o tempo na sociabilidade e nas trocas afetivas que esta possibilita. É o envolvimento com o rap ou com o funk que cria, possibilita e legitima a moratória como uma experiência válida (Dayrell, 2003: 51).

Pretendo, portanto, discutir as especificidades e complexidades dessas práticas culturais juvenis levando em consideração três perspectivas importantes, que organizam a reflexão que será apresentada adiante: 1) A necessidade de se pensá-las como produtos e produtoras de alteridades por meio da produção de imagens, que se definem e se modificam mutuamente a partir da intersecção com as muitas diferenças, tais como idade, geração, gênero, sexualidade, classe, raça, etnia, território etc. Desse modo, conforme o contexto e o que agenciam os interlocutores da pesquisa, as práticas tomam formas e sentidos diversos. Produzem-se, também, como simultaneamente singulares e massificadas. 2) A ênfase na relação com as práticas espaciais nas metrópoles, abordando a forma complexa que as 
apropriações juvenis dos espaços assume num mundo marcado cada vez mais pela deslocalização, mas também pelo território assumido muitas vezes como ancoragem identitária. Arjun Appadurai (1997) demonstra como não há sujeitos ou grupos sociais encarcerados em lugares fechados, mas em profundo deslocamento e comunicação. No mundo contemporâneo, o maior contato com outros lugares e práticas adquire ainda mais força a partir do desenvolvimento das tecnologias de transporte e comunicação. Ou seja, as pessoas cada vez mais se deslocam de seus locais de origem e mesmo aqueles que não têm condições de transitar fisicamente podem fazê-lo por meio da imaginação. As tecnologias da comunicação - a imprensa, a televisão e, de modo ainda mais radical, a internet permitem a todos se imaginar no maior número possível de lugares e posições sociais. Contudo, autores como Akil Gupta e James Ferguson (2000: 36) afirmam que "a ironia de nossa época" está no fato dos lugares e localidades apresentaram-se como cada vez mais "borrados e indeterminados", enquanto "as ideias de locais cultural e etnicamente distintos tornam-se talvez ainda mais proeminentes". 3) A importância de uma reflexão que trate justamente das formas identitárias e de subjetivação contemporâneas articuladas às especificidades das relações de sociabilidade nas grandes cidades. Em outras palavras, as práticas culturais juvenis revelam não apenas o modo como a noção de juventude é construída de diferentes maneiras a partir das articulações dos agentes, mas também como, ao realizarem essas práticas que possuem um forte signo juvenil, estão também recriando ou reinventando o urbano e a cidade que habitam. Trata-se do que Michel Agier (2011) denomina "fazer a cidade", forma pela qual os sujeitos às margens inventam por si a sua própria existência: "são as pessoas que fazem a cidade, os grupos sociais que fazem a cidade, e não a cidade que faz a sociedade" (Agier, 2011: 55). Da mesma forma, eles também tentam produzir uma nova imagem de si, muitas vezes, ao mesmo tempo, em complementaridade e oposição às imagens estigmatizadas que a grande mídia tradicional produz a respeito dos jovens pobres.

Assim, atentar para as práticas culturais juvenis no contexto urbano envolve, como propõe Henri Lefebvre (2008), pensar o urbano para além do urbanismo. Ou seja, deve-se atentar para estas formas particulares de vivenciar e produzir o urbano que, muitas vezes, desafiam e subvertem as lógicas mais gerais e normativas de pensar e regular as atividades dos citadinos. Essas práticas culturais juvenis no espaço urbano criariam o que Lefebvre 
(1991) define como espaços de representação, que se contrapõem às representações dos espaços produzidas pelo urbanismo e às formas hegemônicas de gestão das grandes cidades. Nas palavras de Michel de Certeau (2009), em diálogo com a discussão lefebvriana, trata-se de compreender como essas práticas culturais juvenis tomam em muitos casos a forma de táticas que produzem profundos questionamentos das estratégias dominantes de gestão e organização das cidades. A noção de tática é definida como um “cálculo que não pode contar com um próprio, nem, portanto, com uma fronteira que distingue o outro como totalidade visível" (Certeau, 2009: 45), por isso, ela só tem por lugar aquele que é dominado por outro. Nos contextos das pesquisas aqui abordadas, os protagonistas são fundamentalmente jovens pobres moradores de bairros periféricos de São Paulo, que por meio da criação e articulação de certas táticas conseguem uma inserção mais qualificada na metrópole e, assim, conquistam maior visibilidade. A tática configura-se, portanto, como a arte do fraco, a arte de dar golpes no campo do outro, caracterizada pela ausência de poder, enquanto a estratégia é caracterizada pela presença de um poder que estabelece e domina um espaço que lhe é próprio.

\footnotetext{
O "próprio", do domínio da estratégia, é uma vitória do lugar sobre o tempo. Pelo fato de seu não lugar, a tática depende do tempo, vigiando para "captar no voo" possibilidades de ganho. $\mathrm{O}$ que ela ganha, não o guarda. Tem constantemente que jogar com os acontecimentos para os transformar em ocasiões. Sem cessar, o fraco deve tirar partido de forças que lhes são estranhas" (Certeau, 2009: 46).
}

Atentar para as táticas permite compreender a cidade do ponto de vista criativo dos subalternos. Entretanto, não necessariamente são ações que se contrapõem às lógicas dominantes de organização social e espacial. Portanto, algumas ressalvas devem ser feitas, como a de que não há necessariamente nelas um propósito coletivo transformador. $\mathrm{Na}$ maioria dos casos, elas não configuram comportamentos de oposição ou contestação direta e consciente às estratégias ou lógicas hegemônicas, mas, como demonstra James Holston (2013), manifestam-se pela construção de espaços de cidadania insurgente, que se caracterizam justamente por certas ambiguidades, como a de expressar um forte desejo de aderir à ordem estabelecida e, ao mesmo tempo, por conta disso, criar justamente um efeito contrário por não se enquadrar ou não ser desejado figurando nos espaços que não são considerados seus. Os rolezinhos, passeios coletivos, combinados pela internet, aos 
shopping centers, ocorridos de forma bastante intensa no final de 2013 e início de 2014, foram um exemplo bastante contundente desse processo, pois congregavam jovens que queriam estar nesses centros de compras, por serem considerados espaços de prestígio e reconhecimento, mas que sofreram dura repressão pelo fato de sua presença coletiva ser indesejada e percebida como ameaçadora. Por outro lado, deve-se considerar também que tática e estratégia não são categorias fixas, mas situacionais, o que é tático num contexto, pode tornar-se estratégico em outro.

Quando analiso as práticas das zoeiras dos estudantes nas escolas, por exemplo, o que parece ser apenas uma tática de contraposição à ordem escolar mostra-se também um dispositivo reprodutor de estratégias mais amplas de preconceitos veiculados na grande mídia (Pereira, 2016). A própria noção de juventude, pensada como constructo social, poderia ser compreendida apenas como campo de ação e controle pelo poder, por meio de dispositivos diversos como os de saúde e educação, mas também das próprias "políticas públicas para a juventude". Contudo, sem negar essa dimensão, deve-se argumentar que, se a categoria juventude é uma construção histórica e cultural, ela também produz e permite a criação de novos sentidos pelos agentes sociais. Assim, reduzir a ideia de juventude a apenas uma construção social que permite o exercício de determinados poderes ou biopoderes pode levar a perder de vista a criatividade dos agentes que seriam enquadrados nessa categoria etária, pois seriam entendidos apenas com dominados, agentes passivos, sem capacidade de reflexão e nenhum protagonismo sobre sua vida ou destino. A pesquisa nas escolas, por exemplo, revelou-me que, se essa instituição é uma das principais responsáveis pela configuração do que entendemos hoje pela ideia de juventude, há, atualmente, um processo reverso no qual aqueles que seriam considerados jovens transformam cada vez mais as dinâmicas de funcionamento das escolas pela imposição de suas práticas culturais juvenis, que, em grande medida, desestabilizam as regras disciplinares que regulam e caracterizam tais instituições, criando assim um novo ambiente escolar.

Assim, o que se pretende aqui é justamente, por meio de um olhar etnográfico, demonstrar como essas práticas culturais juvenis situam-se entre táticas e estratégias. Desse modo, pretendo realizar o que José Guilherme Magnani (2002) define como a articulação de um enfoque de perto e de dentro e de longe e de fora que permita, simultaneamente, não 
reduzir as práticas dos agentes aos grandes determinantes sociais: o capitalismo, a desigualdade, o urbanismo, negando-lhes qualquer tipo de agência, mas também não reduzindo a discussão apenas a descrição dos discursos e práticas dos interlocutores da pesquisa, não permitindo reflexões sobre lógicas mais gerais, inclusive as da dominação. Ou seja, parte-se da experiência do antropólogo em campo para a produção de um conhecimento bastante singular que articula suas reflexões com as dos agentes em campo. Paul Willis e Mats Trondman (2008) destacam como a experiência etnográfica proporciona novas formas de compreender o mundo social por possibilitar o encontro da experiência do pesquisador com as de seus interlocutores da pesquisa.

\begin{abstract}
Se quiserem, estamos interessados em produzir efeitos «aha» em que a expressão evocativa através dos dados toca a experiência, corpo e emoções do leitor. Estes são momentos em que novas interpretações e possibilidades são abertas no espaço entre experiência e discurso, desconstruindo e, ao mesmo tempo, dando nova forma ao que é tomado como garantido, numa resposta particular à forma da ordem social, uma resposta que transcende dicotomias como público/privado, social/individual. Estes efeitos fundem velhas e novas experiências, abrindo assim as mentes dos leitores para novos horizontes (Willis; Trondman, 2008: 219).
\end{abstract}

Willis e Trondman reconhecem a importância do papel da teoria como precursora, meio e resultado do estudo e da escrita etnográfica, mas advertem que sempre deve ser uma teoria útil, capaz de se relacionar com a evidência etnográfica. Não pode, portanto, ser uma teoria voltada para si, porque a experiência etnográfica tem de ser capaz de também desestabilizar as teorias com as quais o etnógrafo foi a campo e não apenas se valer da pesquisa empírica para comprovar aquelas.

\title{
Rolês, zoeiras e ostentação
}

Em pesquisa sobre a pixação na cidade de São Paulo, atentei para a relação dos jovens adeptos dessa prática com o espaço urbano (Pereira, 2005). Há entre eles um modo bastante particular de se relacionar com os bairros de origem, nas franjas da cidade, e com as regiões mais centrais, pois valorizam o lugar onde moram e principalmente a própria ideia de periferia, que denominam como quebrada. Por esta, designam o bairro que habitam a partir de uma concepção de espaço de reconhecimento e/ou de pertencimento valorizado positivamente. Neste último caso, as ideias de carência, pobreza e violência perdem 
importância como categorias de estigmatização apenas. Por outro lado, há, entre eles, um movimento de afirmar e valorizar a periferia como local daqueles que enfrentam esses problemas com coragem e, por isso, possuem elementos em comum a serem trocados. Ao mesmo tempo, os adeptos da pixação também escolhem o centro da cidade como o principal e mais atrativo espaço de encontro para deixar suas marcas. Ou seja, ao contrário de uma ideia bastante difundida de gangues que demarcam um território no qual outros grupos juvenis não podem adentrar, na pixação paulistana o que observei foi o estabelecimento de relações para além do bairro ou de um local delimitado. Somente se torna um pixador de verdade quem deixa sua marca nos muros mais distantes do bairro onde se mora, principalmente se estiverem no centro da cidade. Exatamente por isso denominam o ato de pixar por rolê, que seria o mesmo que dar uma volta, ou fazer um passeio, para usufruir da cidade e, nesse caso, marcá-la. Aqueles que têm muitas pixações na cidade são reconhecidos como os que têm muitos rolês e, por isso, merecem o respeito dos pares.

Por meio de seus espaços de encontro no Centro, os seus points, pixadores das mais diferentes localidades da região metropolitana de São Paulo encontram-se para estabelecer vínculos de amizade ou mesmo rivalidade, criando assim, desde os anos 1990, uma espécie de rede social offline. Nela, testam o quanto têm de reconhecimento diante de seus pares. No point, consegue obter grande visibilidade quem realiza mais rolês para marcar a cidade. Os que são considerados pixadores de destaque são cercados pelos mais novos ou menos experientes para dar autógrafos, com os traços de suas pixações, em folhas de papel, em ação conhecida como troca de folhinhas. Por meio dessa atividade, eles constituem acervos de materiais sobre a pixação, pois além das folhinhas, colecionam também recortes de reportagens. O tamanho desse acervo é também um demonstrativo do grau de inserção nessa rede social bastante particular, conferindo prestígio a quem possui os maiores, mais antigos e mais variados arquivos. Por meio do acervo das folhinhas, eles demonstram um grande apreço pela dimensão da memória e, assim, mostram que, além da visibilidade, querem também ser lembrados pelos pares. 
Dessa forma, os pixadores manipulam taticamente o anonimato proporcionado pela metrópole para conseguir fama. Eles realizam uma prática considerada ilegal sem serem identificados, por meio do pseudônimo do grupo ao qual pertencem, grafado na paisagem urbana, mas conseguem, assim, certa fama dentro da rede de relações constituída pela pixação. Quem não é visto não é lembrado, afirmaram-me em diferentes momentos. Nesse processo, utilizam-se das diferentes dinâmicas da metrópole, não apenas se valendo desse paradoxo anonimato/fama, mas também lidando com a lógica de seus espaços. Os pixadores, apesar de se identificarem com a periferia e a afirmarem como valor positivo, têm no Centro o seu espaço principal de encontro e de visibilidade. "Dá mais ibope pixar no Centro", relatavam-me.

Muito comum entre eles é lembrar e reverenciar colegas que já morreram. Desrespeitar a marca de um pixador já falecido configura uma das maiores ofensas que se pode realizar. Esse desrespeito pode ocorrer por um grafite ou outra pixação sobreposta à marca daquele que já não pode voltar para refazê-la no muro. Chamam essa sobreposição de atropelo. Joel Candau (2011: 143) discute a importância da memória dos mortos para a afirmação de identidades coletivas: "todo indivíduo morto pode converter-se num objeto de memória e de identidade, tanto mais quando estiver distante no tempo". Quando os pixadores homenageiam seus colegas mortos, também estão a relatar suas condições de vida e os riscos a que são submetidos e aos quais se submetem cotidianamente, por pixar ou simplesmente por viver em um bairro pobre da periferia marcado por altos índices de violência. Constroem, assim, por meio dessa atividade, um mecanismo social de memória e de reconhecimento, inventando uma cidade bastante particular, que faz sentido, fundamentalmente, para eles, pixadores, que dizem saber ler os muros.

Observei lógica semelhante de busca de visibilidade e reconhecimento em outros dois contextos, o do funk, já citado, e o das escolas públicas de ensino médio em bairros da periferia de São Paulo (Pereira, 2016). Nestas, havia uma prática que me despertou a atenção logo a partir dos primeiros contatos da pesquisa de campo, as zoeiras, que consistem em práticas de gozação, jocosidade e brincadeiras nas relações que os alunos estabelecem entre si, mas também com os professores e a escola de uma maneira geral. Zoar envolve tanto gozar algum colega por causa de sua roupa ou de alguma marca corporal, como interromper as aulas com atitudes que chamam a atenção. Trata-se de uma 
forma de contrapor o tempo de seriedade da instituição escolar, marcado pelas normas disciplinares com horários muito bem programados para a realização de atividades, pela temporalidade juvenil dos estudantes caracterizada justamente pelo não apreço a normas e regras disciplinares. Esse tempo juvenil, como demonstram os autores José Machado Pais (2003), Paul Willis (1991) e Paul Corrigan (1993), define-se muitas vezes, aliás, como um não fazer nada para dar risadas e se divertir com os amigos como forma de sociabilidade. Por meio das atividades lúdicas, os agentes das zoeiras conseguem visibilidade para si. Nas escolas em que estive, as zoeiras davam destaque aos seus principais protagonistas que conseguiam relativa fama e reconhecimento dos colegas, por terem um talento especial de arrancar risadas dos outros estudantes. A maioria dos que se destacavam nas zoeiras eram eleitos os representantes de sala, por exemplo.

Uma das formas de zoar na escola envolve ouvir músicas em alto volume durante o horário das aulas, principalmente pelo smartphone. Houve durante muito tempo uma tentativa árdua dos professores de proibir o uso de tais aparelhos em sala de aula. Porém, pelo menos no período em que realizei a pesquisa, esta foi uma batalha perdida. Nos smartphones, o gênero musical mais ouvido era o funk carioca, principalmente na sua vertente proibidão, que tem como característica falar sobre crime, drogas e sexo. Invariavelmente, nas aulas que acompanhei, havia algum aluno escutando funk apenas para si com o fone de ouvido individual ou sem este acessório para que todos os presentes pudessem ouvir, causando assim nos docentes grande aversão à presença de aparelhos eletrônicos na escola. Houve até a criação de uma lei estadual proibindo o uso de telefones celulares dentro das instituições de ensino. Assim, as escolas públicas em bairros periféricos de São Paulo, que em muito já se assemelham a presídios com suas grades e inúmeros portões e trancas, ganham mais uma característica em comum com essa outra instituição: o temor da presença desses dispositivos de comunicação.

Como se pode perceber, a música funk tem exercido grande influência em uma parcela considerável dos jovens moradores dos bairros periféricos de São Paulo. A esse respeito, em entrevista para um programa de televisão, um MC do chamado funk ostentação deu a seguinte afirmação: "Não só os boys que podem fazer uma faculdade de medicina e ganhar dinheiro, nós da periferia também podemos ganhar dinheiro com o funk". A partir do funk conhecido como proibidão, criado no Rio de Janeiro e exportado 
para a capital paulista e para a região da Baixada Santista no litoral de São Paulo, os jovens paulistas passaram a compor também os seus próprios funks abordando os temas já recorrentes, como crime, drogas, sexo e acesso a bens de alto valor, como carros e motos. Em São Paulo, o estilo torna-se cada vez mais popular entre os jovens de bairros pobres da periferia. Começaram, então, a surgir festas de rua, promovidas a partir do som, em alto volume, de um automóvel. Elas ficaram conhecidas inicialmente como "pancadões", em alusão às fortes batidas eletrônicas da música, e posteriormente passaram a ser denominadas de "fluxos", nesse caso aludindo à grande aglomeração de pessoas. Justamente esse "fluxo" passa a incomodar principalmente a sua vizinhança, que, por sua vez, reclama do som alto e da aglomeração de pessoas a consumir álcool e outras substâncias, que, além disso, obstrui o tráfego de veículos.

Há, assim, uma forte reação do poder público. Destaco aqui duas políticas públicas que objetivam combater tais festas de rua: a repressão e a captura ${ }^{5}$. No primeiro caso, a ação mais comum é feita pela polícia militar, por meio da denominada "Operação Pancadão", que consiste em dispersar os jovens reunidos em certas ruas da cidade a ouvir a música funk. Mais recentemente, a opção pela repressão em São Paulo foi reforçada por um projeto de lei municipal que pró́be qualquer tipo de evento na rua, principalmente os ligados ao funk. O projeto foi criado pela chamada "bancada da bala" da Câmara dos Vereadores de São Paulo, um grupo de vereadores, formado, em sua maioria, por expoliciais, que tem defendido ações mais truculentas do poder público, entre outras posições das mais retrógradas ${ }^{6}$. Já no segundo caso, à repressão aos bailes funks somou-se a atuação pela sua captura e tentativa de domesticação. Em 2009, além da repressão policial aos bailes na rua, a subprefeitura do distrito de Cidade Tiradentes, no extremo leste da cidade, organizou um festival de funk para tentar atrair os jovens que participavam das festas na rua e mesmo transformar sua atuação. Os ganhadores do festival teriam direito a uma gravação em estúdio de sua música em faixas de uma coletânea em $\mathrm{CD}$, mas para tal feito havia algumas regras a serem seguidas, como não poder cantar músicas com palavrões ou que abordassem o crime e a pornografia.

\footnotetext{
${ }^{5}$ Por captura, compreendo, a partir da discussão de Deleuze e Guattari (1997), as ações do Estado ou do poder estratégico que visam domesticar ou controlar atividades que lhe são perigosas ou ameaçadoras, transformando os espaços lisos, mais performativos, em espaços estriados, mais prescritivos.

${ }^{6}$ Sobre os policiais militares em cargos públicos do legislativo em São Paulo, ver a tese de Danilo Cymrot (2014).
} 
Esse contexto de repressão e de tentativas de captura para domesticação por parte de agentes do poder público abriu caminho para o surgimento de uma nova vertente no funk, que começa gradativamente a diminuir as referências à criminalidade para ampliar as citações ao consumo e às marcas de roupas, tênis, carros e bebidas alcoólicas caras. Não se trata, entretanto, de dizer que as alusões ao sexo e ao crime foram eliminadas, pois as mesmas, de certa forma, em muitos casos, ocultam-se sob as referências às marcas de produtos que seriam objetos de desejo. Tem-se, assim, o funk ostentação, que veio a permitir a muitos desses jovens uma ampla circulação por casas noturnas, recebendo cachês que chegavam na época da pesquisa, em 2012, ao valor de até sete mil reais. A mudança no conteúdo das letras também levou a um acesso cada vez maior à grande mídia, principalmente a programas de televisão. Contudo, é justamente por meio das novas mídias que esses jovens têm obtido o destaque e a fama almejada. Muitos cantores de funk passaram a gravar videoclipes exibindo-se em carros importados, com roupas de grife e bebidas caras, acompanhados de mulheres e cantando justamente os elementos que exibiam e ostentavam pelo YouTube. Nesse primeiro momento, o que se tem é principalmente um processo de expor uma ideia do que significaria ser rico, pois a maioria dos MCs vem de estratos sociais muito pobres. É o caso de MC Dede e do próprio MC Guimê, ambos de São Paulo, ou do MC Boy do Charmes, da cidade de São Vicente, na Baixada Santista. Nas primeiras idas a campo em casas noturnas que tocavam funk em São Paulo, era comum ouvir músicas que diziam palavras como Hornet, Hayabusa, R1, Juliete, Ecko Red, Ed Hardy, entre outras. Inicialmente não sabia o que tais termos significavam e, por isso, precisei acessar a internet e, a partir da descoberta dos videoclipes, passei a entender que eram referências a marcas de motos, roupas e acessórios.

Nessa novidade do funk paulista, a ideia do consumo que passou a inspirar o nome desse novo estilo, ostentação, é expressa por meio dos seguintes temas predominantes em suas letras: roupas e acessórios caros ou de grife, carros, bebidas e mulheres. A estética dos videoclipes de funk ostentação inspira-se e lembra bastante a dos videoclipes do gangsta rap estadunidense. As próprias casas noturnas incorporaram essa lógica da ostentação, o que lhes beneficiou, pois lhes aumentou a venda de bebidas consideradas mais caras como uísques, vodcas e energéticos. Como já acontece há tempos em outras casas noturnas mais centrais e frequentadas por público de maior poder aquisitivo, quem compra as bebidas 
mais caras carregam-nas em baldes de gelo enfeitados com artefatos faiscantes, para chamar atenção para si. Além disso, uma das casas noturnas que acompanhei organizava dias especiais, como o Dia da Ed Hardy, no qual quem fosse vestido com alguma roupa dessa marca teria desconto para entrar na casa e mesmo para acessar os camarotes. Outro evento bastante marcante foi a Noite das Naves. Nesse dia, a casa noturna inseriu automóveis tunados ${ }^{7}$ e com sons potentes dentro de seu espaço fechado e, assim, o som partiu dos próprios carros e não do sistema de som da casa. Imitava-se, dessa maneira, a dinâmica das festas nas ruas.

Nessa nova versão do funk produzida pelos paulistas, as novas tecnologias da informação e da comunicação têm exercido um papel fundamental para a sua divulgação e sucesso, principalmente pelas novas possibilidades de uso da imagem e das redes sociais. Por meio de novas mídias como o YouTube, muitos jovens pobres moradores de bairros periféricos de São Paulo, associados em muitos casos a determinados produtores locais, conseguiram alcançar um grande público, mesmo que às margens da mídia tradicional. No caso da produção de imagens, deve-se destacar que no funk ostentação, a criação das letras das músicas associou-se diretamente à produção dos videoclipes, pois se passa a cantar o que se quer exibir e ostentar. O sucesso de um produtor/diretor de videoclipes demonstra justamente a importância desses dois elementos: a imagem e as tecnologias da informação e da comunicação. Trata-se de Konrad Dantas, cujo nome artístico é Kondzilla, morador da cidade do Guarujá, no litoral paulista, que começou a fazer grande sucesso a partir de 2012. Ele já dirigiu e produziu centenas de videoclipes e alcançou com eles, até a escrita deste artigo, mais de 6 bilhões de visualizações em seu canal no YouTube. Somente com o videoclipe da música Plaque de 100, protagonizado por MC Guimê - um dos primeiros cantores de funk ostentação que alcançou maior destaque na mídia tradicional, com música em trilha sonora de abertura de novela da Rede Globo de televisão -, já alcançou mais de 70 milhões de visualizações em 2017.

Nas férias de verão do final de 2013 e início de 2014, o funk ostentação teve um desdobramento curioso que novamente embaralhou as relações entre criminalidade e consumo. As primeiras notícias anunciaram a ocorrência de um baile funk no estacionamento do Shopping Itaquera, na zona leste da cidade, que culminou num grande

\footnotetext{
${ }^{7}$ Carros modificados para, geralmente, adquirir mais potência em seu motor e sistema de som.
} 
arrastão (uma espécie de tumulto coletivo que acarreta em roubos em sequência), embora as próprias reportagens demonstrassem que nenhum lojista havia prestado queixa de roubo ${ }^{8}$. Montou-se forte esquema de segurança na maioria dos shoppings de São Paulo nesse período, com intensa presença policial e mesmo proibição da entrada de pessoas não bemvistas pela administração dos centros comerciais. Num dos rolezinhos que acompanhei em shopping center da zona sul de São Paulo, no domingo anterior às festividades de Natal, a tática da polícia foi a de não deixar os jovens ficarem parados em grupo.

$\mathrm{Na}$ verdade, o que se observou foram encontros, combinados pelas redes sociais, de jovens, fãs de funk ostentação em sua maioria, que queriam fundamentalmente verem e serem vistos, encontrar amigos e paquerar. No shopping, a lógica do zoar, já observada nas escolas, voltou a fazer sentido, pois eles gritavam, zombavam uns dos outros e desfilavam em grandes grupos a bagunçar pelos corredores de lojas. Contudo, tais ações não foram bem recebidas. As correrias e a grande confusão, retratadas pelos telejornais como se fossem jovens causando tumulto para roubar produtos das lojas, o chamado arrastão, eram, na realidade, imagens deles fugindo da repressão policial. Houve, assim, por meio dessa abordagem criminalizante da grande mídia, a criação de um pânico moral sobre tais eventos, que fez com que se inventassem os arrastões nos shoppings paulistanos. Após a repressão, surgiram as iniciativas que tentaram capturar tais ações, como a atuação da prefeitura de São Paulo e de certas empresas e produtores culturais que começaram a organizar rolezinhos em parques e outros espaços mais protegidos e isolados, longe dos centros comerciais da cidade ${ }^{9}$.

\footnotetext{
${ }^{8} \mathrm{Na}$ época, houve matérias com manchetes como: "Vídeo mostra confusão durante arrastão no Shopping Metrô Itaquera", de 08/12/2013, pela revista Veja São Paulo < http://vejasp.abril.com.br/cidades/shoppingmetro-itaquera-arrastao-video> e "Adolescentes fazem arrastão no Shopping Metrô Itaquera", pelo jornal Agora, de 08/012/2013, <http://www.agora.uol.com.br/saopaulo/2013/12/1382586-adolescentes-fazemarrastao-no-shopping-metro-itaquera.shtml $>$

${ }^{9}$ Posteriormente, a partir de 2014 , a abordagem midiática, após o seu primeiro impulso de criminalização rotulando os eventos como arrastão, começou a mudar seu enfoque e abordar os rolezinhos como encontros para lazer e diversão. O próprio poder público passa a entrar no jogo, com o governador Geraldo Alckmin afirmando que os rolezinhos não eram caso de polícia e com a prefeitura de São Paulo oferecendo outros espaços, como o Parque do Ibirapuera para a realização desses encontros.
} 


\section{Criminalização, captura e ambiguidade}

Quando da pesquisa sobre a pixação, a principal tensão que enfrentava em campo referia-se à possibilidade de ser abordado pela polícia. No point dos pixadores, tive de correr várias vezes com eles quando aparecia alguma viatura em alta velocidade e/ou algum policial atirando para cima para dispersar a multidão. Cheguei mesmo a ser abordado e revistado junto com eles por policiais militares, além de ser chamado de "lixo da sociedade" por um sargento. Por isso, ao prosseguir meus estudos no doutorado em Antropologia Social pela USP, defini que não trataria mais de uma prática juvenil específica, mas que tentaria observar o entrecruzamento de muitas delas em espaços periféricos da cidade. Desse modo, em vez de focar num único grupo, abordaria um espaço que congregasse o maior número possível de jovens e suas práticas. Avaliei então que as escolas públicas de ensino médio na periferia seriam cenários reveladores das relações de sociabilidade entre jovens moradores de bairros periféricos de São Paulo. Além da ampliação do enfoque, pensava que, assim, eu conseguiria realizar uma pesquisa mais tranquila, em que a questão da violência e da criminalização dos jovens não fosse tão intensa e próxima como acontecia com a pixação. Esta, na verdade, foi uma grande ilusão, pois, ao circular por quatro escolas públicas de bairros da periferia de São Paulo, presenciei uma criminalização ainda maior dos jovens. Dos professores, por exemplo, ouvi frases como: "Nessa escola só tem tudo bandido", "Eles são perigosos" ou "Bem-vindo à selva".

Nas escolas, a questão da relação entre a juventude pobre e periférica com a criminalidade apareceu basicamente sob duas perspectivas principais: 1) a da criminalização que partia do julgamento de uma parcela considerável dos professores e de alguns integrantes da direção das instituições e 2) a de alguns estudantes que recorriam ao repertório da criminalidade como elemento de interação e mesmo de expressão de poder para, servindo-se da estigmatização que já sofriam, impor medo aos docentes. Alguns deles escreviam a sigla PCC na lousa antes dos professores entrarem em sala de aula, por exemplo. Observei em diversos momentos e contextos como a questão da criminalidade era inserida na sociabilidade dos jovens como elemento comunicacional ou mesmo de afirmação de virilidades. Desde as conversas sobre crimes e a atuação da polícia no bairro onde viviam até o funk proibidão que falava de roubos, tráfico e exaltava as facções 
criminosas de São Paulo e Rio de Janeiro, essa era uma temática recorrente entre os jovens. No caso das músicas que abordavam e mesmo exaltavam práticas consideradas criminosas, elas eram ouvidas na maioria das vezes em alto volume pelos smartphones, com os jovens, aglomerados ao fundo da sala em torno do dono do aparelho que emitia o som, a cantarem juntos. Além disso, o repertório do crime estava nos filmes que assistiam (quando fiz a pesquisa de campo, Tropa de Elite era um grande sucesso entre eles) e mesmo nos games que gostavam de jogar, como GTA (Grand Theft Auto) e Counter Strike.

Numa das escolas que acompanhei, houve um período de explosão de bombas que se inspirava claramente nas ações que o PCC (Primeiro Comando da Capital) realizara em São Paulo, como o chamado "Salve Geral" em $2006{ }^{10}$. Utilizar a criminalidade como repertório de sua sociabilidade não implicava, entretanto, participação em atividades criminosas. Embora não fosse meu objetivo identificar jovens que estavam inseridos na criminalidade, é possível afirmar que a grande maioria daqueles com quem conversei não tinha qualquer inserção no chamado mundo do crime, ainda que esse fosse um tema constante de suas conversas e interações. A questão da criminalidade entra também como repertório das zoeiras estabelecidas pelos estudantes. O que demonstra que essa é uma referência constante, principalmente para os meninos, de afirmação de poder e prestígio. Mesmo na pixação em que a relação com a criminalidade é mais dúbia, pois a própria prática é criminalizada, a distância do mundo do crime, apesar de bastante tênue, também é afirmada em muitos casos. Alguns pixadores chegam a relatar inclusive que estar inserido nessa prática de marcar os muros da cidade impede muitos jovens de ingressarem em atividades criminosas mais efetivas (como roubos e tráfico de drogas), pois a partir do momento que o fizessem ficariam mais vulneráveis e correriam um risco muito maior de serem presos e cumprirem penas pesadas caso continuassem a pixar.

As zoeiras, por sua vez, aumentam a criminalização dos estudantes pobres. Embora não estejam inseridos efetivamente em atividades criminosas, o fato de desafiarem os professores e às vezes servirem-se do repertório do crime como forma de intimidação e zombaria colabora para que a criminalização aumente ainda mais. Isso mostra uma

\footnotetext{
${ }^{10}$ Evento em que o PCC organizou uma série de ataques às forças de segurança do estado de São Paulo. Ele ocorreu em maio de 2006, quando houve rebeliões em presídios, assassinatos de policiais e outros agentes de segurança do Estado e bombas lançadas contra agências bancárias. Logo após esse denominado "Salve Geral", houve uma reação policial violenta com o assassinato de centenas de pessoas em bairros pobres do estado de São Paulo.
} 
especificidade das relações estabelecidas em escolas de ensino médio na periferia, pois, como pude observar, ao acompanhar algumas escolas particulares, embora os estudantes de classe média destas também zoassem e criassem problemas para o desenvolvimento das relações de ensino, com comportamentos que eram muito similares aos que ocorria entre os estudantes pobres, aqueles não eram criminalizados, pois suas ações eram vistas apenas como atos de indisciplina ou de jovens mal-educados e sem limites. Essa estigmatização dos jovens pobres no contexto escolar é inclusive percebida por estudantes pernambucanos por meio de uma categoria, a de cisma. Em pesquisa realizada pelo CEBRAP (Torres et al., 2013), sobre a realidade de escolas públicas no Brasil, há uma descrição de como é comum entre os estudantes da cidade do Recife, em Pernambuco, a afirmação de que têm dificuldades na escola porque certos professores têm cisma deles. Ou seja, eles percebem que são estigmatizados e que, por isso, certos professores têm desconfiança deles.

William Chamblis (1973) pesquisou, nos anos 1970, duas gangues de jovens em escola estadunidense, os Saints e os Roughnecks. O autor demonstra como cada um dos dois grupos era avaliado de forma diferente a partir da posição de classe social predominante entre seus integrantes. Os Saints, de camadas sociais mais favorecidas economicamente, eram considerados de boas famílias e, consequentemente, além de tirarem boas notas, tinham seus atos de transgressão vistos apenas como casos isolados ou como fatos corriqueiros e naturais para a idade. Por outro lado, os Roughnecks não eram tão bem-vistos, pois pertenciam a estratos socioeconômicos menos privilegiados. Eles tinham desempenho escolar fraco e eram sempre apontados como suspeitos, independente do que fizessem. Isso acontecia mesmo com os Saints praticando o maior número de atividades ilegais. Ou seja, o rótulo de delinquente funcionava apenas para o grupo social já marginalizado previamente por sua pior condição socioeconômica, corroborando a discussão de Howard Becker (2008), que afirma a não existência de um comportamento essencialmente desviante, pois o mesmo seria criado socialmente.

O grau em que um ato será tratado como desviante depende também de quem o comete e de quem se sente prejudicado por ele. Regras tendem a ser aplicadas mais a algumas pessoas que a outras. Estudos da delinquência juvenil deixam isso muito claro. Meninos de áreas de classe média, quando detidos, não chegam tão longe no processo legal como os meninos de bairros miseráveis (Becker, 2008: 25). 
Em grandes cidades como São Paulo, com o desenvolvimento das mídias, esse processo de rotulação e estigmatização ganha maior amplitude, pois é possível produzir discursos que alcançam um público maior e mais diversificado, criando posições ainda mais enrijecidas e criminalizantes de certas práticas e segmentos sociais. Produz-se, assim, um fenômeno que é denominado como pânico moral. Como demonstra Stanley Cohen (2011) já nos anos 1960/1970, em pesquisa na Inglaterra, uma das formas mais recorrentes desse pânico moral é associada justamente às práticas engendradas por grupos jovens, cujo comportamento é considerado desviante ou delinquente, sendo muitas vezes associado à violência. Essa dimensão do pânico moral discutido por Cohen - em que a mídia desempenha um papel crucial para propagar representações distorcidas e sensacionalistas sobre determinados eventos, que levam, na maioria dos casos, à criminalização, particularmente quando se tratam de ações protagonizadas por jovens pobres - mostrou-se presente em todas as práticas culturais juvenis que observei. $\mathrm{Na}$ pixação, invariavelmente tem ocorrido uma cobertura que a apresenta como uma prática delinquente e perigosa. Nas escolas públicas voltadas para jovens pobres, as narrativas sobre a chamada violência escolar têm consolidado uma visão bastante recorrente sobre esses estudantes como perigosos e sem nenhuma perspectiva de futuro, como pude constar em conversas com os professores. O funk, por sua vez, já é há tempos no Rio de Janeiro alvo constante de coberturas midiáticas que promovem tal pânico moral. Mais recentemente, os rolezinhos foram os eventos que ilustraram de forma bastante clara como esse fenômeno midiático é produzido.

Os rolezinhos, que inicialmente foram classificados como atividades que visavam promover crimes em sequência nos shopping centers, os chamados arrastões, receberam diferentes rotulações dos mais variados atores, propagando representações particulares sobre esses eventos e sobre os jovens que deles participaram. Do primeiro rótulo, o de ação criminosa, os rolezinhos passaram também a ser compreendidos e classificados, principalmente por determinados segmentos ligados a movimentos sociais e políticos, ora como protestos contra a segregação na metrópole, cujo shopping center é um dos principais símbolos, ora como ação de jovens alienados que apenas querem consumir desenfreadamente. Houve, inclusive, a organização de rolezinhos de protesto por movimentos sociais contra o racismo e mesmo por movimentos de trabalhadores sem-teto. 
Assim, de ação criminosa, os rolezinhos passaram a ser interpretados, de modo divergente, simultaneamente, como uma forma de protesto político e como comportamento "alienado" de vítimas do consumismo. A própria grande mídia, que criminalizou no início, mudou o tom, entrevistando os meninos e as meninas que protagonizaram esses eventos para tentar demonstrar que não se tratava de ação política, mas de jovens apenas à busca de consumo e diversão no shopping. De certa forma, os rolezinhos geraram representações que são muito comuns quando se trata de jovens pobres no Brasil: a de criminosos, a de vítimas e a de heróis portadores de certo protagonismo e potencial de transformação política. Muita tinta sobre esse evento ser o resultado da ascensão da chamada "Nova Classe C" também foi gasta, ignorando que o referido desejo por bens de consumo e por reconhecimento e visibilidade não foi uma grande novidade, pois como demonstra Heitor Frúgoli Jr. (1989), no final dos anos 1980, já ocorriam apropriações dos espaços fechados dos shopping centers da cidade como lugar de encontro e estabelecimento de sociabilidades juvenis. $\mathrm{O}$ que de inédito os rolezinhos dos anos de 2013 e 2014 na verdade apresentaram foi o movimento de maior conexão de jovens pobres com as novas tecnologias da informação e da comunicação e, com isso, a exploração de suas muitas potencialidades para o encontro e usos do espaço urbano.

De certa forma, práticas culturais juvenis como os rolezinhos, a pixação, as zoeiras dos alunos e mesmo o funk podem transitar por todas essas representações e também escapar a todas. Não devem, de modo simplista, ser enquadradas em apenas um único aspecto. As zoeiras dos estudantes, por exemplo, poderiam, num primeiro olhar mais romântico, ser consideradas apenas como reação a uma opressão do dispositivo disciplinar da escola, mas elas próprias também reproduzem certas opressões quando replicam padrões machistas, homofóbicos e racistas nas relações jocosas que engendram. Assim, um aluno que fuja ao que é classificado como o padrão de sucesso ou de normalidade é não apenas vítima constante de gozações como também de humilhações e mesmo perseguições. Nesse sentido, essas práticas podem também ser lidas na chave das insurgências discutidas por James Holston (2013). A própria ocupação dos bairros na periferia da cidade de São Paulo é a expressão fundamental dessa cidadania insurgente, forma encontrada para tentar habitar e sobreviver no mundo urbano, muitas vezes na costura entre a reivindicação política contestadora e a prática clientelista. Portanto, essas insurgências não necessariamente se 
apresentam como resistência, pois, em muitos casos, também se associam ao hegemônico, ainda que continuem provocando incômodos.

\section{Considerações finais}

A partir da inserção em diferentes momentos e lugares de pesquisa, a pixação entre os anos de 2001 e 2007, as sociabilidades juvenis nas escolas entre 2006 e 2010 e o funk ostentação entre 2012 e 2014, abordei aqui o modo como diversificadas práticas culturais juvenis, protagonizadas por jovens que moram ou que se identificam com a periferia de São Paulo, desenvolvem-se, fundamentalmente, em três âmbitos: do lazer, da fruição dos espaços urbanos e da busca por reconhecimento e visibilidade. Não por acaso, a ideia de rolê - uma referência direta às ideias de circulação e fruição da cidade, estabelecendo práticas de lazer - é uma categoria utilizada em dois contextos, no da pixação, cujos adeptos denominam as saídas para pixar como rolês, e no dos próprios rolezinhos. Sobre essa dimensão dos usos juvenis do tempo livre, José Machado Pais (2003) afirma que haveria hábitos bastante comuns entre os grupos juvenis, como o de "matar o tempo", que compreenderia sair, divertir-se ou, como no caso em questão, fazer um rolê. Encontrar-se para não fazer nada seria uma das atividades mais importantes das culturas juvenis, afirma o autor. E esse fazer nada envolve, fundamentalmente, estar com os amigos a conversar. “Os assuntos das conversas não têm de ser reais, podem ser histórias fictícias, imaginárias, irreais - tanto mais interessantes quanto mais divertidas" (Pais, 2003: 131) ${ }^{11}$. O sair para se divertir, segundo Machado Pais, levaria a uma quebra no cotidiano por meio das sociabilidades grupais e de uma organização coletiva do tempo, na qual se procura o lado festivo da vida. Nesse sentido, o não fazer nada seria apenas aparente, pois, por meio dessas associações para desfrutar do ócio, os jovens desenvolveriam formas efetivas de participação social que reforçariam coesões grupais.

\footnotetext{
${ }^{11}$ Em grande conformidade com a própria noção de sociabilidade de Georg Simmel (2006), definida como uma forma de sociação que se caracteriza pela satisfação do estar junto ou socializado.
} 
Nas três práticas que observei, as atividades de lazer apresentavam-se como espaços privilegiados de conseguir reconhecimento e visibilidade. No caso da pixação, essa dimensão é fundamental, pois, em meio ao anonimato que uma metrópole proporciona, é possível escrever em muros de modo não autorizado sem ser identificado e, ao mesmo tempo, alcançar certa fama dentro do grupo do qual se faz parte. Quem mais pixa em lugares de mais destaque e risco é identificado como alguém que tem mais rolês pela cidade e, assim, é mais admirado pelos pares. Consegue, por meio dessa prática, obter fama dentro de um grupo específico, aproveitando-se do anonimato da metrópole. Nas escolas, as zoeiras são também, além de um meio de impor um tempo liberado das obrigações e da disciplina escolar, uma forma de se alcançar grande popularidade diante dos colegas. No funk ostentação, por sua vez, o principal objetivo dos videoclipes produzidos é justamente conseguir o maior número de visualizações e, em seguida, um grande público para os seus shows. No caso dos rolezinhos, muitas vezes, após os encontros nos shoppings, os jovens perguntavam nas redes sociais por quem os tinha visto nos eventos, demonstrando a importância do ver e ser visto.

Um dos produtores de videoclipes de funk da cidade de São Paulo, conhecido como Montanha, da Funk TV, situada no bairro de Cidade Tiradentes, contou-me, certa vez, que o funk ostentação produziria, como nas novelas da televisão, imagens de uma realidade de luxo que não existe para a maioria. A diferença dos videoclipes de funk ostentação estaria no fato de que os sujeitos que estão imersos numa imagem de luxo são também jovens da periferia de São Paulo: “É uma realidade com a qual o moleque da periferia se identifica ou pode se imaginar parte, porque quem está lá é de um estrato social muito parecido". Ele ainda prosseguiu apontando para relações com outra prática cultural juvenil das periferias de São Paulo, o hip hop. Segundo Montanha, o rap e o hip hop levaram a política e a possibilidade de ter voz, um espaço de expressão, para os jovens das periferias de São Paulo, enquanto o funk proporcionou um espaço de lazer, capaz de congregar homens e mulheres. Não se pode tomar essa dimensão como uma representação totalizante dessas práticas, pois o hip hop também se configura como um importante espaço de lazer, da mesma forma que o funk abre espaço para diferentes formas de expressão política, mas é possível pensar que haveria uma tendência maior do primeiro à articulação política e do 
segundo à articulação festiva e de lazer. De certo modo, em São Paulo, o funk pode ser visto como uma transformação do hip hop, com rupturas e continuidades ${ }^{12}$.

Vivemos um contexto em que cada vez mais os sujeitos se encontram deslocalizados, conforme aponta Arjun Appadurai (1997). Os jovens que acompanhei, seja pela pixação, pelas zoeiras nas escolas, ou pelos adeptos do funk ostentação e seus rolezinhos nos shoppings, estão justamente mostrando esse desejo de circulação e a ambiguidade dos territórios nas grandes cidades. No mundo contemporâneo, intensifica-se o movimento de valorização do lugar de onde se é nativo concomitantemente ao desejo das pessoas quererem cada vez mais estar em tantos outros e diferenciados lugares. Pela pixação, apesar da afirmação da periferia como espaço que lhes confere certa marca identitária, é no Centro que se quer estar, se encontrar e obter visibilidade. No funk ostentação, ainda que a periferia desponte como espaço de reconhecimento, como acontece na pixação, e muitas músicas de funk exaltem a humildade de quem vem de tais lugares marginalizados como um valor, é por meio do consumo de grifes e mesmo pela presença em shopping centers, como se viu nos rolezinhos, que afirmam e buscam reconhecimento. Mesmo na zoeira dos estudantes, que questionam a escola como espaço de disciplinarização, há também a celebração desta como espaço de encontro juvenil.

Appadurai (1997) destaca essas novas possibilidades de deslocamentos na contemporaneidade por intermédio de dois importantes e interconectados elementos: a migração e as mídias. Segundo ele, os dois exercem efeito conjunto sobre o trabalho da imaginação, considerada um traço constitutivo da subjetividade moderna. Assim, a imaginação torna-se uma prática social, que assume um papel fundamental, pois, mesmo que não se desloquem fisicamente, as pessoas, pela força dos meios de comunicação, podem, cada vez mais, imaginar-se em outros lugares. As tecnologias da comunicação fornecem ferramentas que permitem pensar-se como um projeto social em curso. A imaginação, afirma esse autor, saiu do âmbito expressivo da arte para a vida cotidiana, não sendo necessariamente totalmente emancipadora, nem inteiramente disciplinadora. Appadurai (1997) ainda faz uma distinção entre as ideias de imaginação e fantasia. A primeira teria um caráter de projeto e de ações efetivas e mesmo coletivas, já a segunda, a

\footnotetext{
${ }^{12}$ Para mais sobre o desenvolvimento do hip hop e sua relação com o funk em São Paulo, ver o texto de Márcio Macedo (2016).
} 
fantasia, não teria esse caráter projetivo e de ação, sendo mais individualista e mesmo egoísta. Todas as práticas culturais juvenis aqui analisadas possuem essas duas potencialidades, a de um projeto social coletivo e até emancipador e a de uma fantasia autocentrada e bastante imediatista. Conforme tão bem ilustra esse trecho da música Nóis de Nave, cantada por MC Boy do Charmes ${ }^{13}$ :

\begin{abstract}
Imaginei, sorrindo eu tô na favela. Sou Robbin Hood, eu mato e morro por ela. Sei que a inveja continua rodiando a gente. Sou sofredor, mas tô botando aí na chapa quente. Eu consegui comprar minha linda XT. O meu Megane e a 1100 tá vindo por aí. Fui imaginando, e quem imagina levanta a mão. Por ser humilde, eu tenho um sonho e não é em vão. Vamo imaginando nóis de Porsche ou de Mercedes Benz, de Captiva, de BMW ou de 1100 .
\end{abstract}

Guy Debord, no seu famoso livro A sociedade do espetáculo, afirmará que "tudo que era diretamente vivido se esvai na fumaça da representação" (Debord, 1997: 13). Ele define o espetáculo não pelo conjunto de imagens produzidas, mas por um mundo em que as imagens são as grandes mediadoras das relações sociais. Assim, se para esse autor a aparência torna-se o vivido, ações como a do MC Boy do Charmes e a de MC Bejinho, apresentada na introdução do texto, demonstram uma tentativa desses jovens de utilizarem dessas relações imageticamente mediatizadas a fim de produzir um vivido que se aproveita desse mundo das aparências. Ou seja, servem-se da sociedade do espetáculo como uma forma de produzir uma imagem sobre si, que destoa daquela convencionalmente propagada pelas mídias tradicionais, embora se aproveitando dela como forma de projetar-se socialmente. Em outras palavras, se a sociedade do espetáculo separa, segundo Debord, o vivido da representação, priorizando a última, as práticas culturais juvenis constituem para muitos jovens, justamente, a oportunidade de criar, pela representação, as condições para novas vivências ou mesmo para sua sobrevivência.

\footnotetext{
13 Nóis de Nave é uma música de 2012, de autoria do próprio MC Boy do Charmes. Para assistir ao videoclipe: <https://www.youtube.com/watch?v=ckHt1qD_TDs>; acesso em: 16/01/2017.
} 


\section{Referências}

AGIER, Michel. Antropologia da cidade: lugares, situações, movimentos. São Paulo: Editora Terceiro Nome, 2011.

APPADURAI, Arjun. Modernity at Large. Minneapolis: University of Minnesota Press, 1997.

ARIÈS, Philippe. História social da criança e da família. Rio de Janeiro: Zahar, 1978.

BECKER, Howard. Outsiders: estudos de sociologia do desvio. Rio de Janeiro: Jorge Zahar, 2008.

BOURDIEU, Pierre. "A juventude é apenas uma palavra". In: . Questões de sociologia. Rio de Janeiro: Marco Zero, 1983.

BUCHOLTZ, Mary. Youth and cultural practice. Annual Review of Anthropology, 31, out. 2002, p. 525-552.

CANDAU, Joël. Memória e identidade. São Paulo: Contexto, 2011.

CERTEAU, Michel de. A invenção do cotidiano: artes do fazer. Petrópolis, RJ: Vozes, 2009.

CHAMBLISS, William. The Saints and Roughnecks. Society, 11, 1, nov./dez. 1973, p. 24-31.

COHEN, Stanley. Folk devils and moral panics: The creation of the Mods and Rockers. London and New York: Routledge, 2011.

CORRIGAN, Paul. Doing Nothing. In: HALL, Stuart; JEFFERSON, Tony (orgs.). Resistance through rituals; youth subcultures in post-war Britain. London, Hutchinson and Co, CCCS. University of Birmingham, 1993.

CYMROT, Danilo. Polícia militante: deputados policiais militares na Assembleia Legislativa do estado de São Paulo (1999-2011). Tese de Doutorado (Direito/Criminologia), Universidade de São Paulo, 2014.

DAYRELL, Juarez. O jovem como sujeito social. Revista Brasileira de Educação, nº 24, set./dez. 2003, p. 40-52.

A escola "faz" as juventudes? Reflexões em torno da socialização juvenil. Educação \& Sociedade, vol. 28, n. 100, out. 2007, p. 1105-1128.

DAYRELL, Juarez; MOREIRA, Maria Ignez; STENGEL, Márcia (orgs.). Juventudes contemporâneas: um mosaico de possibilidades. Belo Horizonte: Ed. PUC Minas, 2011.

DEBORD, Guy. A Sociedade do Espetáculo. Rio de Janeiro: Contraponto, 1997

DELEUZE, Gilles; GUATTARI, Félix. Mil Platôs - capitalismo e esquizofrenia, vol. 5. São Paulo: Editora 34, 1997.

FRÚGOLI JR., Heitor. Os shopping centers de São Paulo e as formas de sociabilidade no contexto urbano. Dissertação de Mestrado (Antropologia Social), Universidade de São Paulo, 1989.

GUPTA, Akhil; FERGUSON, James. "Mais além da "cultura": espaço, identidade e política da diferença". In: ARANTES, Antonio (org.). O espaço da diferença. Campinas, SP: Papirus, 2000, p. 30-49.

HOLSTON, James. Cidadania Insurgente: disjunções da democracia e da modernidade no Brasil. São Paulo: Companhia das Letras, 2013.

LEFEBVRE, Henri. The production of space. Oxford: Blackwell Publishing, 1991. . A Revolução Urbana. Belo Horizonte: Ed. UFMG, 2008.

MACEDO, Márcio. Hip-Hop SP: transformações entre uma cultura de rua, negra e periférica (19832013). In: KOWARICK, Lúcio; FRÚGOLI JR., Heitor (orgs). Pluralidade urbana em São Paulo: vulnerabilidade, marginalidade, ativismos. São Paulo: Ed. 34; Fapesp, 2016, p. 23-53.

MAGNANI, José Guilherme. De perto e de dentro: notas para uma etnografia urbana". Revista Brasileira de Ciências Sociais. São Paulo, ANPOCS/Edusc, vol. 17, n.49, jun., 2002, p. 11-29.

MARGULIS, Mario; URRESTI, Marcelo. La juventud es más que una palabra. Margulis, Mario. (org.). La juventud es más que una palabra. Buenos Aires: Biblos, 1996.

PAIS, José Machado. Culturas Juvenis. Lisboa: Imprensa Nacional - Casa da Moeda, 2003.

PEREIRA, Alexandre Barbosa. De "rolê" pela cidade: os "pixadores" em São Paulo. Dissertação de Mestrado (Antropologia Social), Universidade de São Paulo, 2005. 
“A Maior Zoeira” na Escola: experiências juvenis na periferia de São Paulo. São Paulo: Editora da Unifesp, 2016.

SIMMEL, Georg. Questões Fundamentais da Sociologia: indivíduo e sociedade. Rio de Janeiro: Jorge Zahar Ed, 2006.

TORRES, Haroldo et al. O que pensam os jovens de baixa renda sobre a escola. São Paulo: CEBRAP/Fundação Victor Civita, 2013. Disponível em: <http://www.fvc.org.br/estudosepesquisas/2012/pdf/relatorio_jovens_pensam_escola.pdf $>$.

WILLIS, Paul. Aprendendo a ser trabalhador: escola, resistência e reprodução social. Porto Alegre: Artes Médicas, 1991.

WILlIS, Paul; TRONDMAN, Mats. "Manifesto pela etnografia". Educação, Sociedade \& Culturas, $\mathrm{n}^{\circ}$ 27, 2008, p. 211-220.

Recebido em: 22/05/2017.

Aprovado em: 28/06/2017. 